\title{
Isolation of the Drosophila segmentation gene runt and analysis of its expression during embryogenesis
}

\section{J. Peter Gergen and Barbara A. Butler}

Department of Biochemistry and Molecular Biology, The University of Texas System Cancer Center, M.D. Anderson Hospital and Tumor Institute at Houston, Houston, Texas 77030 USA

runt is one of the genes required for establishment of the segmented body pattern of the Drosophila embryo. We have isolated DNA sequences containing this gene using P-element transposon tagging. Southern blot analyses of six different DNA rearrangements that are associated with runt mutations revealed a minimal region of 8.5$\mathrm{kb}$ of DNA that was important for function. In germ line transformation experiments, a 14.5-kb segment of DNA that spanned this minimal region provided significant, although not full, levels of runt activity. The runt gene encoded a 2.6.kb poly(A) ${ }^{+}$RNA that underwent a series of dynamic changes in its spatial and temporal patterns of accumulation during embryogenesis. The runt RNA was most abundant at the blastoderm stage when it showed the seven stripes of expression characteristic of other Drosophila pair-rule genes.

[Key Words: runt; Drosophila segmentation gene; P-element transposon tagging; in situ hybridization; germ line transformation]

Received March 21, 1988; revised version accepted July 1, 1988.

The formation of the segmentation pattern in the Drosophila embryo provides an excellent model system for investigating the mechanisms of body pattern formation in higher organisms. Extensive genetic analyses have revealed a relatively small set of genes that play central and specific roles in this process. These genes have been grouped into two broad classes, depending on whether the primary requirement is maternal or zygotic. The emerging picture is that the maternal genes are responsible for imparting both polarity and a global coordinate system to the early embryo (Schupbach and Wieschaus 1986; Nüsslein-Volhard et al. 1987). These maternal cues are responded to subsequently by the zygotic genome in a localized and position-dependent manner.

The zygotic segmentation genes were initially grouped into three classes based on the size and periodicity of the pattern of defects observed in mutant embryos (Nüsslein-Volhard and Wieschaus 1980): (1) Gap gene mutations that cause deletions of contiguous groups of segments, (2) pair-rule mutations that cause deletions spaced at two-segment intervals along the anteroposterior axis, and (3) segment-polarity mutations that do not affect the number of segmental repeats, but instead alter the patterning within segments. Genes from each of these three classes have been isolated, and the cloned DNAs have been used to generate probes for examining their patterns of expression during embryogenesis. These results provide substantial support for the original classification scheme. The cloned representatives of the gap gene class, Krüppel $(K r)$ and hunchback $(h b)$, are both expressed over large domains within the regions affected by the respective mutations (Knipple et al. 1985; Tautz et al. 1987). Similarly, all of the pair-rule genes examined to date show a pair-rule pattern of RNA accumulation for at least some period of time during early embryogenesis. And finally, several segment-polarity genes are expressed with an every segment periodicity (Fjose et al. 1985; Kornberg et al. 1985; Baker 1987; Baumgartner et al. 1987; Cote et al. 1987; Rijsewijk et al. 1987).

The existence of these three classes suggests that the process of segmentation involves the sequential establishment of patterns within successively smaller regions of the embryo. The first evidence in support of this comes from genetic and morphological experiments indicating that the gap and pair-rule genes act at a stage prior to the segment-polarity genes (Nüsslein-Volhard and Wieschaus 1980). The molecular data on the times of expression of these genes during normal embryogenesis further support this idea. The most compelling evidence for such a hierarchical flow of positional information comes from the recent examination of the regulatory interactions between several of the different genes. In this hierarchy, the maternal effect genes influence the patterns of gap gene expression (Gaul and Jackle 1987). The gap genes in turn are required for normal ex- 
pression of the pair-rule genes (Carroll and Scott 1986; Ingham et al. 1986; Frasch and Levine 1987), and the effects of pair-rule mutations on the expression of the engrailed (en) segment-polarity gene indicate hierarchical interactions between these two classes (Howard and Ingham 1986; DiNardo and O'Farrell 1987). Maternal effects are observed on the expression patterns of pair-rule genes (Ingham et al. 1985; Mohler and Wieschaus 1985; Carroll et al. 1986), as are the effects of gap mutations on segment-polarity gene expression (Ingham et al. 1986). However, it is possible that these alterations are indirect and may be due solely to the effects on more upstream genes.

Examination of pair-rule gene expression patterns in embryos mutant for different pair-rule genes has revealed an apparent hierarchy of interactions within this class. In particular, the pair-rule genes even-skipped $(e v e)$, hairy $(h)$, and runt are involved in regulating the expression of fushi tarazu (ftz) (Carroll and Scott 1986), whereas reciprocal effects of $f t z$ mutations have not been observed on the expression of $h$ (Howard and Ingham 1986) or eve (Harding et al. 1986). The pair-rule genes runt and $h$ also influence the expression of eve (Frasch and Levine 1987), thus suggesting that these two genes play key roles in the establishment of the reiterated pair-rule pattern.

The runt gene is one of the best characterized segmentation genes with respect to genetic and morphological criteria. Analyses of embryos mosaic for runt mutations indicated that the effects on pattern formation are primarily cell autonomous (Gergen and Wieschaus 1985). This suggests that the gene product is not involved in generating positional information via long-range interactions that span several cell diameters but rather in the local translation of positional information by individual cells. The phenotypes produced by different runt mutations indicate that within the cells requiring runt there are quantitative differences in the level of requirement (Gergen and Wieschaus 1986). More significantly, extra doses of the wild-type gene cause pattern deletions that are out of phase with but overlap those caused by strong loss-of-function mutations /Gergen and Wieschaus 1986). This not only shows that runt can affect cells that normally do not require the gene but also suggests that some cells are sensitive to either loss or gain of activity, i.e., they have an obligate requirement for an intermediate level of activity. In this report we extend the analysis of this pair-rule gene to the molecular level by cloning it and examining its pattern of expression during embryogenesis.

\section{Results}

\section{Isolation of DNA from the runt locus}

The 'P-element transposon tagging' strategy was used to obtain DNA from the runt locus. Three different hybrid dysgenesis-induced runt mutations (Zusman et al. 1985) were screened using in situ hybridization to polytene chromosomes for the presence of P-element DNA at the runt locus. A positive hybridization signal was observed at the correct cytological position (over X-chromosomal band 19E2) in animals heterozygous for the 50-2 mutation, the expected result if this mutation was due to the insertion of a $\mathrm{P}$ element. The other two mutations did not show any signs of P-element hybridization in this region. One of these, the 34A mutation, was associated with a chromosome inversion with one break in band 19E2 and the other in band 18A. The other dysgenic allele, PV1, appeared cytologically normal.

The 50-2 mutation was taken through five rounds of backcrosses to 'M-strain' Drosophila to reduce the number of unwanted $\mathrm{P}$ elements in the genome. Total genomic DNA was isolated from three of the different Drosophila sublines carrying the 50-2 mutation, and the number of $P$ elements remaining in each subline was determined by Southern blot hybridization. A genomic $\lambda$ library was made from the subline with the fewest $P$ elements (three), and this library was screened for P-element-containing clones. Analysis of restriction enzyme digestion patterns allowed the positive phages to be sorted into three groups. In situ hybridization to polytene chromosomes of wild-type larvae indicated that clones from one group contained DNA from band 19E2. DNA fragments were isolated from these clones and used to screen a wild-type genomic $\lambda$ library. Fragments from the wild-type clones obtained in this way were then used to rescreen the wild-type library for overlapping clones. The resulting set of wild-type clones generated a 'chromosome walk' of $50-\mathrm{kb}$. A restriction map of this walk and the placement of the clones within the walk is shown in Figure 1.

\section{DNA rearrangements associated with runt mutations}

The 50-2 chromosome contains a $1.1-\mathrm{kb} \mathrm{P}$ element inserted at a site designated as map position 0 in Figure 1. The size of this insertion was determined by comparing restriction maps of genomic clones from the 50-2 library (e.g., 26K3a in Fig. 1) and the wild-type library (e.g., I2-3 in Fig. 1). Southern blot hybridization to digests of cloned 50-2 DNA with P-element probes confirmed that this insertion was P-element homologous. The 50-2 insertion is associated with a single additional HindIII site. This presumably corresponds to the HindIII site present in all P elements at a position $29 \mathrm{bp}$ from one of the ends (O'Hare and Rubin 1983). The exact placement of the 50-2 insertion relative to the flanking restriction sites indicated on the map in Figure 1 assumes this to be the case and was determined by mapping the HindIII site. A more definitive molecular characterization of the 50-2 insertion awaits sequence analysis of both mutant and wild-type DNAs.

Several other runt mutations have been screened for the presence of DNA rearrangements in this region. The screening procedure involved Southern blot analysis on genomic DNA isolated from adult Drosophila heterozygous for each runt allele tested. The other $\mathrm{X}$ chromosome was either the parental chromosome used in the hybrid dysgenesis screen or a wild-type chromosome 


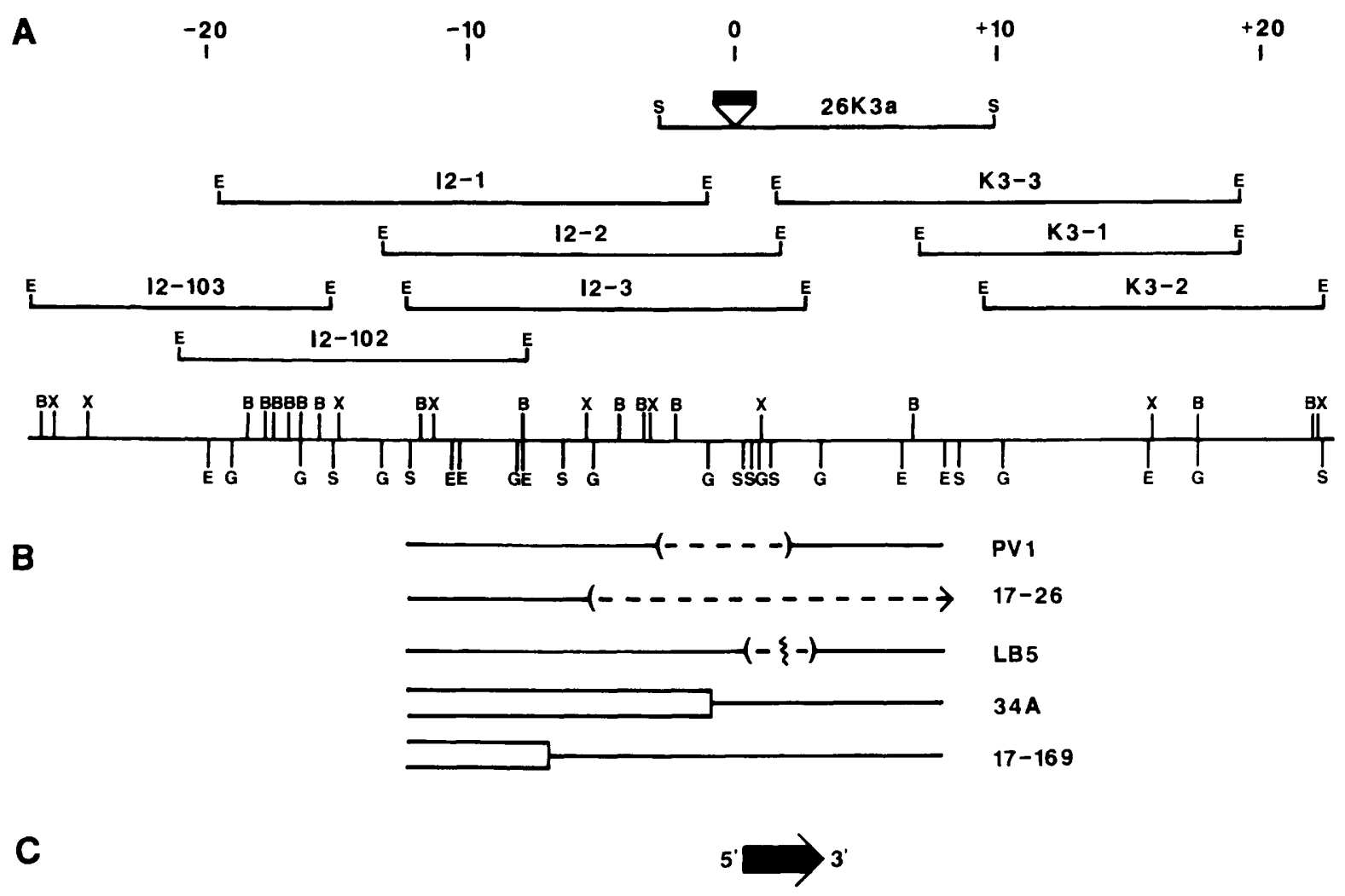

Figure 1. Molecular map of the runt region. (A) Segments of DNA from the runt region that were isolated in bacteriophage $\lambda$ clones are indicated as horizontal lines. Each segment is labeled with its clone designation. A composite restriction map for the region is given below these. The restriction enzyme recognition sites shown are: (B) BamHI, (E) EcoRI, (G) BglII, (S) SalI, and (X) XhoI. The coordinates for the map are shown at the top of the figure. The scale is in kilobases of DNA. The 26K3a clone is one of those isolated from a library made with the DNA from Drosophila carrying the 50-2 runt mutation. This library was generated by ligating DNA partially digested with Sau3a into the BamHI site of EMBL3. The Drosophila DNA insert is excised with SalI as indicated on the figure. The position of the P-element insertion in 50-2 DNA is shown on this clone. The site of insertion is designated as coordinate 0 on the map. The other clones are all from a partial digest library made with wild-type (Oregon R) Drosophila DNA in EMBL4. In this library the cloned DNA is excised with EcoRI. $(B)$ The structures of five different DNA rearrangements that have been identified in this cloned region are diagramed. All of these rearrangements are associated with runt mutations. The allele designation of each is given to the right of its representation. Solid lines represent regions that are apparently unaffected on the mutant chromosomes. The dashed lines represent DNA that has been deleted. The open boxes represent DNA from other chromosome regions that has been brought into juxtaposition with the runt region in a chromosome rearrangement. In these two cases only the chromosome carrying the runt transcription unit is shown. The vertical line within the deleted interval of LB5 indicates that this rearrangement is apparently complex. The data described in Fig. 2 indicate this mutation is associated with a deletion of DNA within the interval shown. However, the data also indicate that this is not simply a deletion but involves an insertion or other type of rearrangement. The derivations of the representations for all of these rearrangements are given in detail in the legend to Fig. 2. $(C)$ The orientation and approximate limits of the runt transcription unit are diagramed. The results leading to this conclusion are presented in the text.

from the Oregon $\mathrm{R}$ stock used to generate the $\lambda$ library described above. When the I2-3 segment of cloned DNA was used as a hybridization probe, five of these mutations, including the two others induced by dysgenesis, produced novel fragments indicative of rearrangements in the region. The differences were not due to polymorphisms for single restriction sites because new bands were produced with at least two different restriction enzymes for each mutation. Each of these mutations has been characterized further using other cloned segments from the walk. Where appropriate, smaller subcloned fragments from the region have also been used as hybridization probes to localize the rearrangements more pre- cisely. Representative examples of Southern blots with each of these five mutations are shown in Figure 2. The results of these analyses are diagramed in Figure 1B. The dysgenic PV1 allele and the 17-26 and LB5 alleles all appear to be associated with deficiencies of some DNA from the region. The other two mutations, $34 \mathrm{~A}$ and 17-169, are apparently associated with reciprocal breaks between this region and other chromosome regions. All five mutations were associated with DNA rearrangements within an $8.5-\mathrm{kb}$ interval. These data provide strong evidence that this region of DNA contained at least part of the runt locus.

Some insights about the structure of the locus can be 
Figure 2. DNA rearrangements associated with runt mutations. This figure shows autoradiograms of Southern blots of DNA isolated from Drosophila heterozygous for five different runt mutations. In each case the lane containing the mutant DNA $(\mathrm{m} /+)$ is paired with a sample of wild-type DNA $1+1+1$ that has been digested with the same restriction enzyme and electrophoresed in a neighboring well on the same gel. These paired samples were blotted together and hybridized simultaneously with the different probes described below. Two different wild-type DNAs have been used in these experiments. They are from the Oregon $\mathrm{R}$ strain, or from flies homozygous for In (1) $s c^{8}$ chromosomes. We have observed no differences in the restriction enzyme patterns obtained with these two wild-type samples. The particular digests and probes for each set of lanes are listed below. (Lanes PV1) Two pairs of lanes of DNAs digested with SalI are shown. The pair on the left was hybridized with $\lambda$ clone $\mathrm{I} 2-3$. In the wild-type sample, a fragment of $5.8-\mathrm{kb}$ and two fragments of $7-\mathrm{kb}$ are detected. These two larger fragments are not resolved, and one of them is less intense because it contains only $1.4-\mathrm{kb}$ of homology to I2-3. In the PV1 sample, in addition to these bands, a new band of about 10-kb is detected. The intensity of this novel fragment indicates that it contains only $3-4-\mathrm{kb}$ of homology to I2-3. The pair of PVI lanes on the right was hybridized with a subclone containing an $E c o$ RI fragment that extends from +6.5 to +8.1 on the map in Fig. 1. This fragment detects the weaker of the 7-kb bands detected with I2-3, and in the PV1 lane also detects the same novel $10-\mathrm{kb}$ fragment detected with $12-3$. These results are consistent with a deletion of $5-\mathrm{kb}$ of DNA between the Sall sites at coordinates -6.5 and +8.7 which also

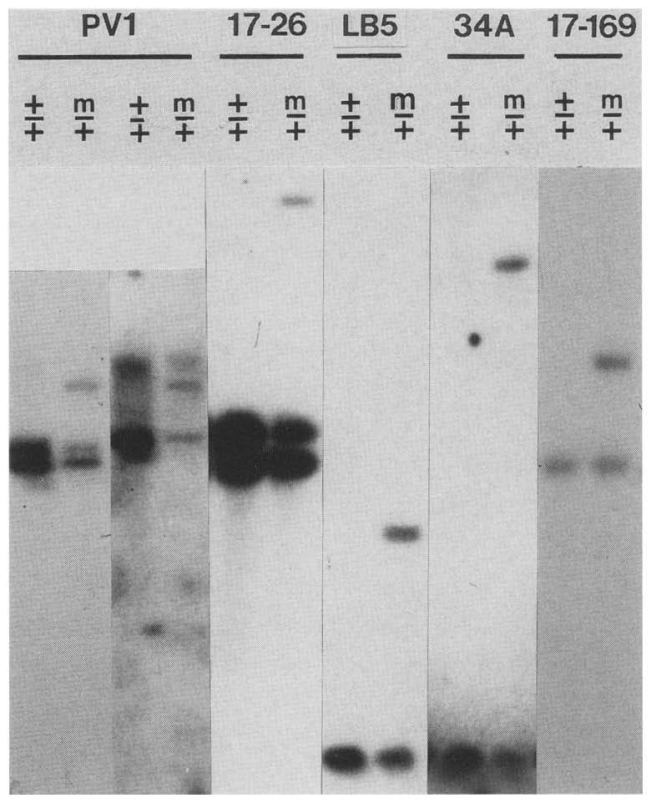
spans the three SalI sites clustered around +1 . Data consistent with a deletion spanning the BamHI site at -2.1 and the XhoI site at +1.1 have also been obtained with samples digested with these enzymes (Lanes 17-26). The DNAs were digested with Sall and hybridized with the I2-3 probe thus giving the same wild-type bands observed above for PV1 samples. A large, weakly hybridizing novel fragment is detected in the 17-26 sample. Based on its intensity this fragment contains only about $1-\mathrm{kb}$ of homology to the probe. A single novel, weakly hybridizing fragment was also detected with an EcoRI fragment probe extending from -8 to +6.5 . Densitometric scans indicate that in this case the novel band contained $2.5 \cdot \mathrm{kb}$ of homology to the probe. These data indicated a breakpoint between -8 and +2.7 with a deletion of most of this interval. The signal intensities obtained in other experiments suggested that this deletion spans probes to the right of -2 , including all of $\lambda$ clone K3-3. Based on these data the left end of the deletion is placed at $-5.4(\sim 1-\mathrm{kb}$ from the Sall site at -6.4 and $2.5-\mathrm{kb}$ from the EcoRI site at -8$)$. (Lanes $L B 5)$ The DNAs have been digested with $B g I I I$ and probed with a subcloned BgII plus Sall fragment $(-0.8$ to +0.5$)$. The presence of a novel fragment in the LB5 sample indicates a breakpoint in the BglII fragment extending from -0.9 to +1 . A novel band was not detected using this same probe on SalI digested DNA. Therefore the breakpoint is to the right of the Sall site at +0.5 . Based on signal intensities in BglII digests probed with I2-3 there is a deletion of DNA spanning from the BglII site at +1 to the site at +3.4 . Densitometry of the novel fragments detected in EcoRI digested DNA suggested a deletion of 2.6-kb of DNA in the interval between -8 and +6.5 . However, if the LB5 chromosome contained only a deletion of DNA within this EcoRI fragment, then only one novel band should have been detected in an EcoRI digest. Hybridization of this probe to two novels band $(5.5-\mathrm{kb}$ and $13-\mathrm{kb})$ indicated this rearrangement is more complex, as indicated in Figure 1. The right breakpoint of the LB5 deletion has not been localized precisely with subcloned probes and its placement is based on the densitometric data. (Lanes 34A) The DNAs were digested and probed as described for LB5. As for LB5, the novel band indicates a break between -0.9 and +1 . The hybridization signal intensity of this novel band is low in this case because the DNA was not partially hydrolyzed before transfer to nitrocellulose. Two novel bands of approximately equal intensity were detected with a subcloned BamHI + Sall fragment that extends from -2.1 to +0.5 . This result suggested that breakpoint is in the middle of this interval, very near to the BglII site at -0.9 . The detection of only one novel fragment with the $B g I I I$ probe is consistent with a break just to the right (within $<0.1 \mathrm{~kb}$ ) of this site. (Lanes 17-169) The DNAs were digested with SalI and probed with a subcloned EcoRI fragment that extends from -10.4 to -8 . The novel fragment indicates a break between the $S a$ II sites at -12.3 and -6.4 . New BamHI bands were not detected with this same probe but were found with the I2-3 probe. In the blots with I2-3, the $B a m H I$ fragment from -7.9 to -4.4 was reduced in intensity in 17-169 heterozygotes. These data place the breakpoint between the BamHI site at -7.9 and the SalI site at -6.4 .

deduced from a comparison of the above molecular results with previous genetic characterizations of these mutations (Gergen and Wieschaus 1986). The three deficiencies (PV1, LB5, and 17-26) all produce null phenotypes. The most informative of these three was PV1. This mutation is apparently due to a deletion of approximately $5-\mathrm{kb}$ of DNA. Genetic information essential for the production of any runt activity, (perhaps part of the structural gene) should therefore be contained within this small interval. By contrast, the 50-2 insertion and the 34A and 17-169 rearrangements all produced only partial loss-of-function phenotypes. This suggests that none of these mutations are associated with a break in the structural gene.

\section{Characterization of the runt transcription unit}

The runt transcription unit was identified and localized using a cDNA probe made from poly $(\mathrm{A})^{+}$RNA isolated from 2- to 4-hr-old embryos. This stage was chosen because genetic and morphological studies have indicated that runt expression is required at or around the cellular blastoderm stage (Nüsslein-Volhard and Wieschaus 1980). This occurs at about $3 \mathrm{hr}$ of development. This is 
also the time at which several other segmentation genes are most abundantly expressed (Hafen et al. 1984; Ingham et al. 1985; Kilcherr et al. 1986; Macdonald et al. 1986). This radiolabeled cDNA probe was hybridized to a Southern blot of selected restriction digests of the recombinant DNA clones spanning the runt region walk shown in Figure 1. Fragments from both the I2-3 and K3-3 clones gave a hybridization signal with this probe. These clones were hybridized to Northern blots of embryonic poly $(\mathrm{A})^{+}$and total RNA. Both detect a single predominant $2.6-\mathrm{kb}$ poly $(\mathrm{A})+\mathrm{RNA}$. A fragment from the right end of the I2-3 insert was subcloned and also detected this RNA. The subcloning vector had promoters for the T3 and T7 RNA polymerases flanking the polylinker site of insertion. Single-stranded RNA probes were made using these RNA polymerases and hybridized to Northern blots to determine the direction of transcription. The in vitro RNA, synthesized $5^{\prime}$ to $3^{\prime}$ from right to left on the map in Figure 1, detects the putative runt RNA (Fig. 3a). This indicated the in vivo RNA was transcribed $5^{\prime}$ to $3^{\prime}$, from left to right as indicated in Figure 1. This figure is drawn with the $5^{\prime}$ end of the RNA near the SalI site at map position 0.5. This tentative conclusion was based on the lack of hybridization to this RNA with any subcloned fragments that contain DNA only on the upstream side of this Sall site. These data do not rule out the possibility that there are one or more very small exons upstream of this site.

The I2-3 subclone was used to screen several stagespecific cDNA libraries. Fifteen different cDNA clones

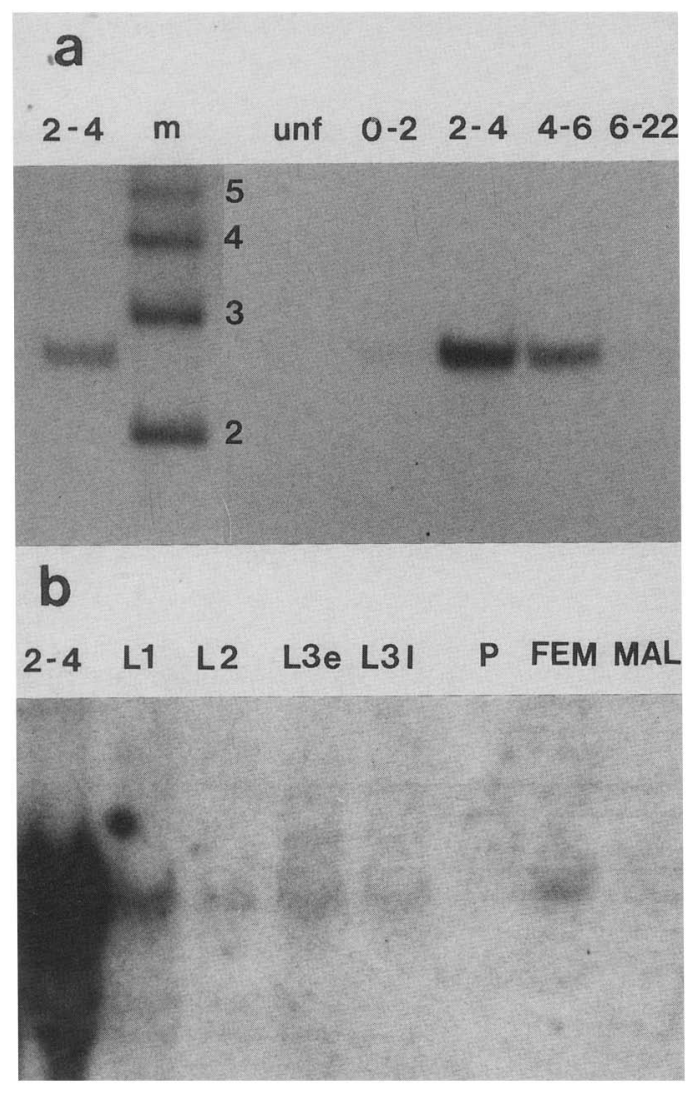
$5 \mu \mathrm{g}$. were obtained from these libraries. None of these clones had the 2.6-kb insert expected for a full-length cDNA, but several contained inserts over $2-\mathrm{kb}$ in length. One of these clones (E6-20) was used in subsequent hybridization experiments. Northern blots of RNA from several different embryonic and post-embryonic stages are shown in Figure 3. These experiments showed that this 2.6-kb poly $(\mathrm{A})^{+}$RNA was most abundant from 2 to $4 \mathrm{hr}$ of embryonic development. It could also be detected in younger and older embryos but was present at only very low levels after $6 \mathrm{hr}$. Somewhat surprisingly, this transcript was detected in RNA isolated from larvae of all stages and from adult females (Fig. 3B). This later expression was at much lower levels (greater than 100-fold difference in abundance) and it is not known if it has any biological significance.

\section{Complementation of runt mutations with a segment of cloned DNA}

Definitive proof that a region of cloned DNA contains a gene can be obtained by demonstrating that the DNA is capable of providing activity in a genetic complementation test. We used the method of P-element-mediated germ line transformation (Rubin and Spradling 1982) to reintroduce a segment of cloned runt genomic DNA into the Drosophila germ line and then assay it for activity. The segment chosen was a $14.5-\mathrm{kb}$ EcoRI fragment spanning from -8 to +6.5 on the map in Figure 1. This fragment contained most, if not all of the transcription unit, as described above. It also encompassed the three known breakpoints in the region that partially eliminated gene function and probably did not disnupt the transcription unit. This segment was not present in intact form in any of the original genomic clones. Therefore a new library of Drosophila DNA digested with $E c o R I$ was generated in the $\lambda$ vector EMBL4. To guarantee that the clones represented functional alleles of runt, the DNA was isolated from Drosophila isogenic for the $\mathrm{X}$ chromosome. $\lambda$ clones containing the $14.5-\mathrm{kb}$

Figure 3. Northern blot analysis of runt RNA. Autoradiograms of Northern blots hybridized with single-stranded RNA probes are shown in both panels. (a) The probe was synthesized from a template of subcloned genomic DNA extending from coordinates -2.1 to +2.5 on the map in Fig. 1. The probe was synthesized $5^{\prime}$ to $3^{\prime}$ from right to left on this map and therefore detected RNAs that were transcribed in the opposite direction. Probes of the opposite polarity did not detect any RNAs in similar experiments. (Lane $m$ ) DNA size standard. The sizes of the bands are given in kilobases. The lane marked unf contains $1 \mu \mathrm{g}$ of poly $\mid A)^{+}$RNA from unfertilized eggs. The other lanes contain similar loadings of RNAs isolated from staged collections of Drosophila embryos. Staging of the embryos is given in hours of development at $25^{\circ} \mathrm{C}$ across the top of the panel. (b) A similar Northern blot with a single-stranded RNA probe that was synthesized off a cDNA subclone template. Total RNA samples isolated from the following developmental stages are shown: (Lanes 2-4) 2- to 4-hr-old embryos, (L1) first instar larvae, (L2) second instar larvae, (L3e) early (feeding) third instar larvae, (L3I) late (climbing) third instar larvae, $(P)$ tanned pupae, (FEM) adult females, and (MAL) adult males. The embryonic and larval lanes each contain $10 \mu \mathrm{g}$ of RNA. The pupal and adult lanes each contain 
EcoRI fragment were isolated from this library, and the fragment was then subcloned into the transformation vector CaSpeR (V. Pirrotta, pers. comm.). This vector carries a truncated version of the white $(w)$ gene, which serves as a convenient dominant marker for identifying transformants.

This construct was injected into Drosophila embryos homozygous for a mutation in $w$, along with DNA of the P-element construct 'wings-clipped' (Karess and Rubin 1984). This helper DNA provided transposase activity but is itself incapable of integration. Surviving $G_{o}$ adults were mated to $w^{-}$flies and germ-line integration events were recovered as $w^{+} G_{1}$ progeny. From a total of 130 surviving $G_{0}$ adults, we recovered two independent germ-line transformation events. In both cases the transposons mapped to the third chromosome and the chromosomes were homozygous viable. The transposons were tested for runt activity by assaying their ability to rescue Drosophila from the lethal effects of several different runt mutations. Based on this assay neither of the transposons was able to compensate fully for the effects of a null mutation in the runt locus. We therefore concluded that these transposons did not provide full runt function since one dose of runt is normally sufficient for viability.

Two lines of evidence indicated that the transposons provided some runt activity. The first was their ability to rescue animals from the lethal effects of several different partial loss-of-function runt mutations. Six different mutant alleles (YP17, YC28, 34A, EA14, P235, YE96; see Gergen and Wieschaus 1986) were tested in this assay and in four cases we obtained adult males hemizygous for these otherwise normally lethal mutations. Among these rescuable alleles, the proportion of rescued progeny correlated approximately with the strength of the mutation. In all cases, some of the rescued adults displayed pattern abnormalities such as missing legs or abdominal segments. The expressivity of these phenotypes also correlated roughly with the strength of the different mutant alleles. The two alleles for which we did not obtain adult males (P235, YE96) were the two partial loss-of-function mutations with the strongest phenotypes. For the weaker of these two (P235), we were able to dissect pharate adults from the pupal cases. These animals had multiple segmental pattern defects.

The second line of evidence for the activity provided by the runt transposons came from examining the cuticle phenotypes of mutant embryos. The leftmost panel in Figure 4 shows the strong segmentation phenotype observed in animals hemi- or homozygous for a null allele of runt (XA06). The other two panels of this figure show representative examples of the phenotypes observed in animals carrying this same runt allele and one of the two transposons. Very similar phenotypes were observed in analogous crosses with the other transposon. These phenotypes resembled those produced by weak lethal alleles of the runt locus (see Fig. 4 legend for a more detailed description). From these results it is not clear whether the lack of full rescue was strictly quanti- tative and could have been overcome by changing the site of insertion or by increasing the copy number of these transposons. This remains an important issue in terms of defining the functional limits of the entire gene and is being pursued. However, the results of these germ-line transformation experiments did demonstrate that the region of cloned DNA contained most if not all of the runt gene.

\section{The pattern of runt expression during embryogenesis}

The technique of in situ hybridization was used to examine the spatial and temporal patterns of runt RNA accumulation during Drosophila embryogenesis. Singlestranded RNA probes radiolabeled with ${ }^{3} \mathrm{H}$, but otherwise analogous to those used for the Northern blots, were synthesized from an E6-20 cDNA subclone template. These probes were hybridized to sections of formalin-fixed Drosophila embryos embedded in paraffin wax, and positive hybridization signals subsequently were detected by autoradiography.

At the stage we have first detected accumulation of the runt RNA it was found localized over a broad domain extending from approximately $10 \%$ to $70 \%$ egg length (EL) along the anteroposterior axis $10 \% \mathrm{EL}=$ posterior pole). An example of this early pattern in a nuclear cycle 13 embryo is shown in Figure 5A. Early in nuclear cycle 14 , a pair-rule periodicity of seven stripes of RNA accumulation became apparent. The most anterior stripe was the first one to become distinct. Alternatively stated, the gap between the eventual first and second stripes was one of the first to form. (It is perhaps more useful to describe the process as the generation of gaps in the pattern of RNA accumulation rather than as the production of stripes as the initial expression pattern was essentially uniform.) At the time the gap between the first and second runt stripes appeared, a clear but smaller gap also developed between the third and fourth stripes and there is frequently a small gap between the fifth and sixth stripes (Fig. 5B). Thus, it seems there was a tendency for the initial gaps to be formed in every other double-segment repeat. The smaller initial size of the more posterior gaps could be interpreted as an indication that they were being established later. This suggests the superposition of an anterior to posterior temporal gradient on this early double-double-segment pattern. Consistent with this idea, the first gap to form in the other double-segment frame was the most anterior one, i.e., the gap between the second and third stripes. The gaps between stripes four and five and between stripes six and seven were not well resolved until the nuclei were clearly elongated and the process of cellularization was well under way.

From the time of nuclear elongation to the completion of cellularization, the runt pattern consisted of seven distinct stripes of RNA accumulation (Fig. 5C). The stripes were broader than the intervening gaps, especially the most posterior stripe (the seventh) which ultimately resolved into two separate domains. The gaps expanded with time, but even at their broadest stage (2-4 


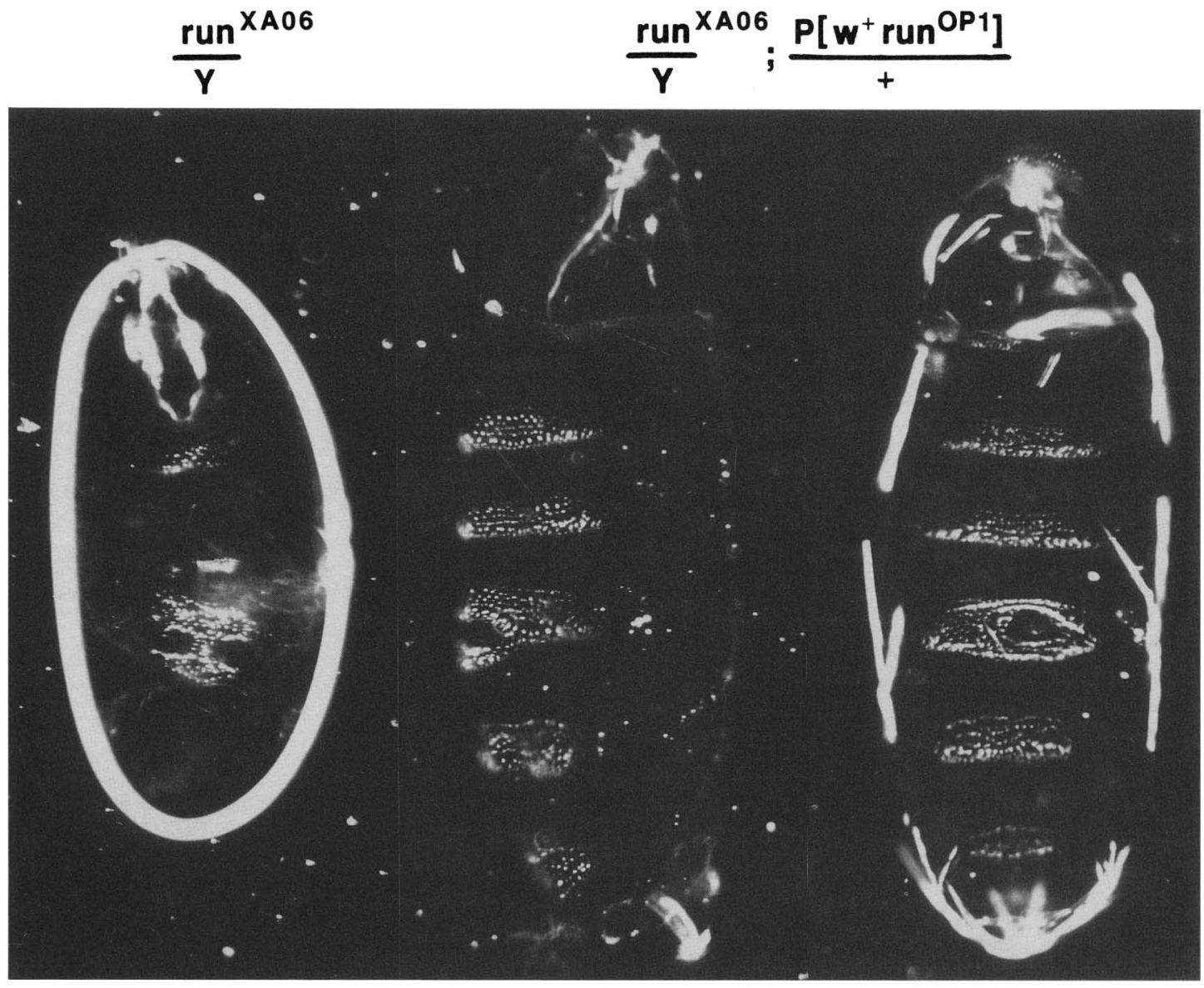

Figure 4. Modification of the runt null phenotype by a P-element transposon. The figure shows dark-field photomicrographs of cuticle preparations of three Drosophila embryos. The embryo on the left is a mutant for the null (XA06) allele of runt. This embryo is still inside the vitelline membrane. The two on the right also carry the XA06 mutation but are also heterozygous for one of the P-element transposons described in the text. These embryos were all derived from the same set of sibling females that were heterozygous for XA06 and were crossed to runt ${ }^{+}$males that were also heterozygous for the transposon. This cross generated these two different genotypes (and phenotypes) in equal proportions. In similar crosses using homozygous transposon-carrying males, no embryos with the null phenotype are recovered. In the null phenotype only three abdominal denticle belts are readily observed (bands of white dots in these photographs). These correspond to mirror-image denticle belts for the region of second and third and the sixth and seventh abdominal segments and an abnormal belt for the eighth abdominal segment (for a detailed description see Gergen and Wieschaus 1986). The embryos with the transposon contain five readily distinguishable abdominal denticle belts. The region containing the second and third abdominal segments is essentially normal, and in both of these embryos only a partial fusion of the fourth and fifth abdominal belts is observed. (Note that the region containing the fourth and fifth belts is almost entirely eliminated in the null condition.) There is only a single belt for the region of the sixth and seventh abdominal segments but it is of normal polarity, unlike that in the XA06 embryo.

cells wide) they are not as big as the stripes (4-6 cells). The stage at which this distinct seven-banded pattern of accumulation was present was also the stage at which the RNA was most abundant. The relative abundance at different stages of embryogenesis is accurately represented by the six different embryos shown in Figure 5 . These embryos were all processed together in the same paraffin block and the examples shown are all from the same section of this block on the same in situ hybridization slide. Therefore, these have been hybridized and washed identically and the signals are from equivalent autoradiographic exposures.

Just prior to the completion of cellularization and the onset of gastrulation, the abundance of RNA dropped in the striped regions. At this same stage the runt RNA reappeared in the regions between the stripes (Fig. 5D,E), and the pattern evolved from a double- to a single-segment mode of expression. This single-segment mode was maintained throughout the process of germ band extension (Fig. 5F). Transcripts from runt appeared in two regions outside of the original domain of expression. Just prior to the completion of cellularization, transcripts appeared in a dorsal anterior region corresponding to the head (Fig. 5D,E). This domain extended from 75 to $85 \%$ EL. Head region expression also persisted during germ-band extension. The runt transcript 


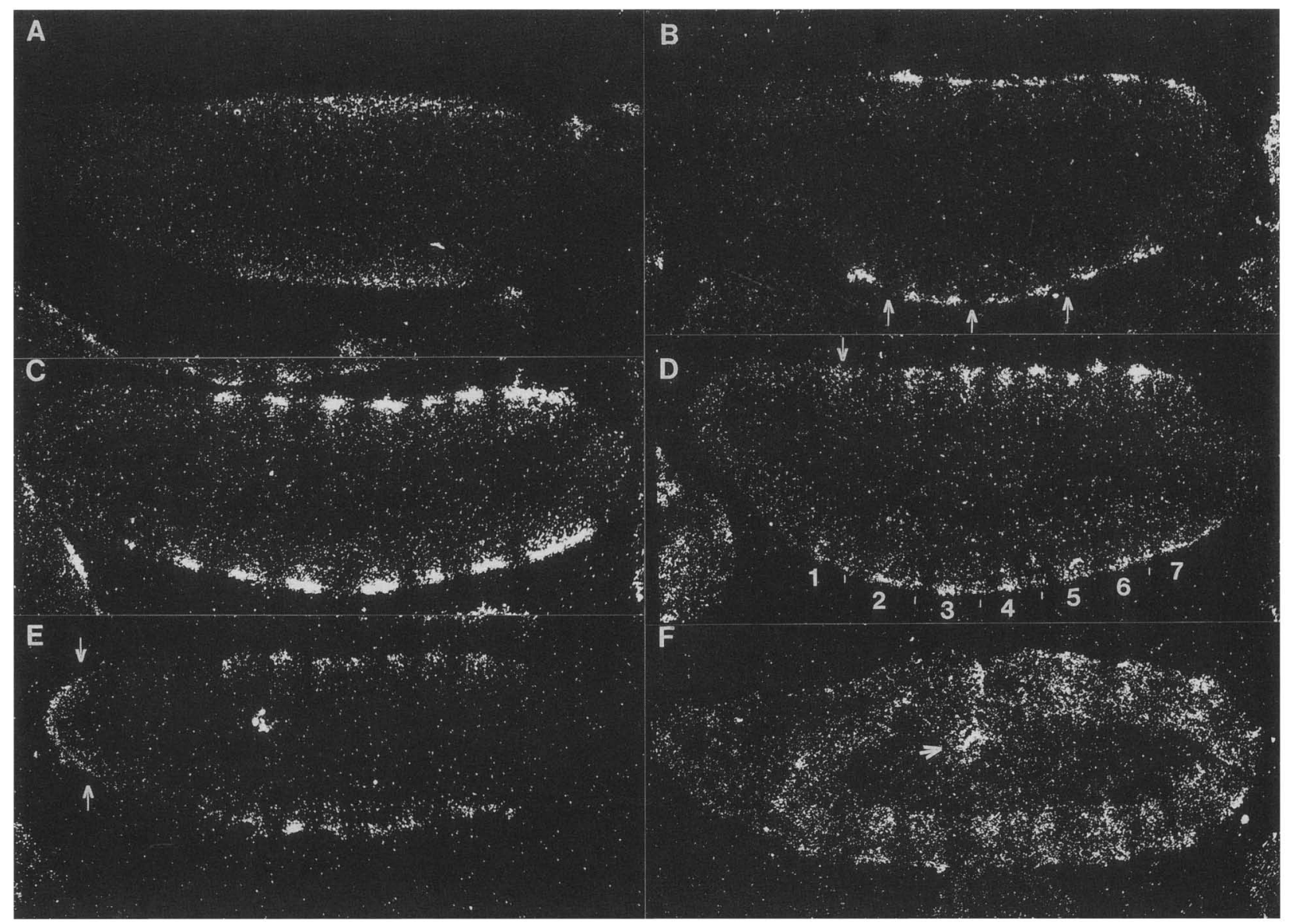

Figure 5. The spatial pattern of runt expression during embryogenesis. The figure shows dark-field photomicrographs of sections of six wild-type Drosophila embryos hybridized with ${ }^{3} \mathrm{H}$-labeled RNA probes that detect runt transcripts. These embryos were all processed and hybridized together and are from a single section of the same in situ hybridization slide. The autoradiographic exposure was 21 days. In each case anterior is to the left, and, in all but $(E)$ the dorsal side is on the top. $(A)$ An embryo in nuclear division cycle 13 with a broad domain of runt expression. $(B)$ An embryo early in nuclear cycle 14 where the first signs of periodicity in the pattern of runt expression become apparent. The arrows indicate the gaps between the presumptive first and second, third and fourth, and fifth and sixth stripes. $(C)$ Blastoderm-stage embryo in the process of cellularizing with seven distinct stripes of RNA accumulation. $(D)$ Cellular blastoderm. Pair-rule periodicity is still apparent but RNA has started to reaccumulate in the gapped regions, making it seem less distinct. The arrow indicates a new domain of runt expression in a dorsal-anterior region. (E) Frontal section of gastrulating embryo. Arrows indicate expression in head region, and lines are to mark regions of accumulation between the original seven stripes. (F) Extended germ-band stage embryo with RNA accumulation in an every segment pattern. The arrow indicates the expression in the proctodeal primordium.

also accumulated in a region posterior to the seventh original stripe during the process of germ-band extension (Fig. 5F). This region corresponded to the proctodeal primordium.

We compared the pattern of runt expression with that of several other segmentation genes. This knowledge is important for understanding how the different patterns of expression relate to the genetic requirements and we hope will help in the interpretation of the regulatory interactions between different segmentation genes. We observed clear pair-rule periodicity in the runt pattern at early stages, prior to the establishment of periodicity in the pattern of expression of the pair-rule gene $f t z$. This temporal relationship is consistent with the known regulatory effects of runt on the expression of $f t z$ (Carroll and Scott 1986). To compare the evolution of the $f t z$ and runt stripes, autoradiographic silver grains were counted in serial sections of a set of embryos hybridized with these two probes. Firm conclusions could not be drawn from the data obtained from any one embryo, and it was not straightforward enough to average the data from different embryos because of slight differences in stage or orientation. However, several significant trends do emerge from this analysis. Figure 6 shows data for six late blastoderm embryos arranged in order of increasing developmental stage. In each embryo the runt stripe was as broad or broader than the $f t z$ stripe. The accumulation of grains across the stripes was not uniform. In the younger embryos, there was a clear tendency toward a higher concentration of grains in the center of each 
stripe than at the margins (Fig. 6). Two arguments can be made that these differences were real and not simply due to scatter of autoradiographic grains. First, in theory the path length of the particles emitted from ${ }^{3} \mathrm{H}$ should only be $0.5-1 \mu$, and the graded differences observed spanned greater than $5-\mu$ intervals. Second, in practice tighter and more uniform grain distributions were obtained for $f t z$. The most striking differences between the blastoderm expression patterns of these two genes were observed at late stages when the $f t z$ stripes narrowed to less than $15 \mu$ (corresponding to three expressing cells). At this stage, the runt stripes are broader than $25 \mu$ (Fig. $6 \mathrm{E}, \mathrm{F})$ and appeared to be broader than runt stripes at earlier stages.

The phasing of the expression pattern of different pairrule genes is best determined by examining the patterns in early gastrulae where morphological markers aid in the alignment of serial sections. At this stage $e v e$ and $f t z$ display complementary, seven-striped, pair-rule patterns of expression (Harding et al. 1986; Macdonald et al. 1986; see also Fig. 7). In both cases the stripes are approximately three cells wide, and approximately one cell, without either transcript, separates adjacent stripes. At this stage the runt pattern was in the process of going from a double- to a single-segment periodicity and the abundance of the RNA was falling. Within this less distinct overall pattern the domains of the seven original stripes could be identified based on their relative width and spacing. The anterior margin of the first runt stripe appeared to lie in the middle of the first eve stripe just within the region of the cephalic furrow (Fig. 7). The runt stripes had a more significant overlap with the $f t z$ stripes but did not appear to span them completely (Fig. 7).

The expression patterns of the pair-rule genes $h$ and paired (prd) have previously been compared to $f t z$ (Ingham et al. 1985; Kilcherr et al. 1986). The relative alignment of $h$ is of special interest as $h$ and runt have approximately reciprocal effects on the expression of other pair-rule genes (Carroll and Scott 1986; Howard and Ingham 1986; Frasch and Levine 1987). The relative alignments of $h$ and runt with $f t z$ suggest that $h$ and runt are almost exactly out of phase with each other. Direct examination of the expression patterns of these two genes both at the time of gastrulation and during the earlier stages of cellularization confirmed this prediction (data not shown). The runt stripes spanned the gaps between the $h$ stripes and appeared to overlap them along both anterior and posterior edges.

We have observed the early accumulation of $\mathrm{Kr}$ mRNA to be in a broader domain than that previously described (Knipple et al. 1985). This is at a time when the periodicity in the runt pattern was first becoming apparent. The runt pattern could thus be used to determine the extent of $K r$ expression relative to the pair-rule genes. This early $K r$ domain spanned the presumptive second, third, and fourth runt stripes and almost extended into the fifth runt stripe. This region comprised $\sim 20$ nuclei (Fig. 8A,B). A $\mathrm{Kr}$ domain of only $12-14 \mathrm{nu}-$ clei, similar to that described previously, was observed

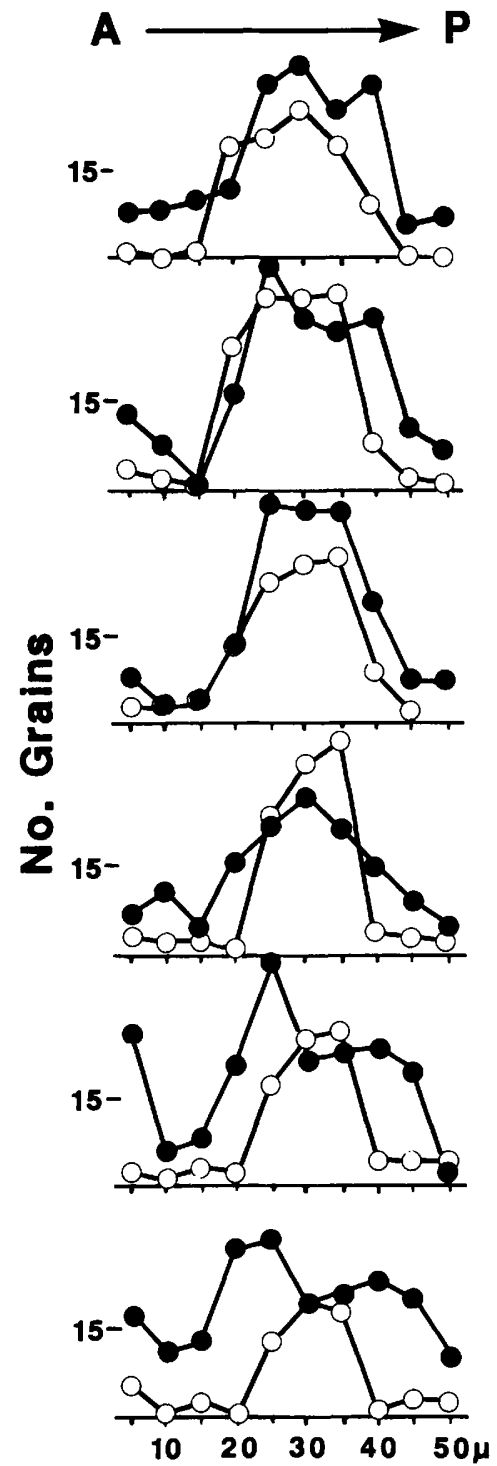

Figure 6. The evolution of $f t z$ and runt stripes. The distribution of autoradiographic silver grains across the regions containing the second $f t z$ and the second runt stripes for six different blastoderm stage embryos are shown. (ㅇ) Data for $f t z ;(\bullet)$ runt. The data for all of these embryos were obtained from the same two consecutive sections. Counts were determined at $5-\mu$ intervals along the anteroposterior axis. This distance approximates the diameter of blastoderm cells. Each point indicates the grains counted in a $50 \mu^{2}$ area $(5 \mu \times 10 \mu)$.

in embryos only slightly older, thus suggesting that the broader expression of $K r$ was very transient. This narrower domain just spanned the third and fourth runt stripes (Fig. 8C,D). This suggests that $K r$ expression was being eliminated from both the anterior and posterior ends of the original broader domain.

There was a difference in the localization of the $K r$ and runt RNAs within the cortical cytoplasm. The runt RNA was most concentrated in a region of apical cytoplasm between the nuclei and the outer membrane. A similar localization was observed for other pair-rule 


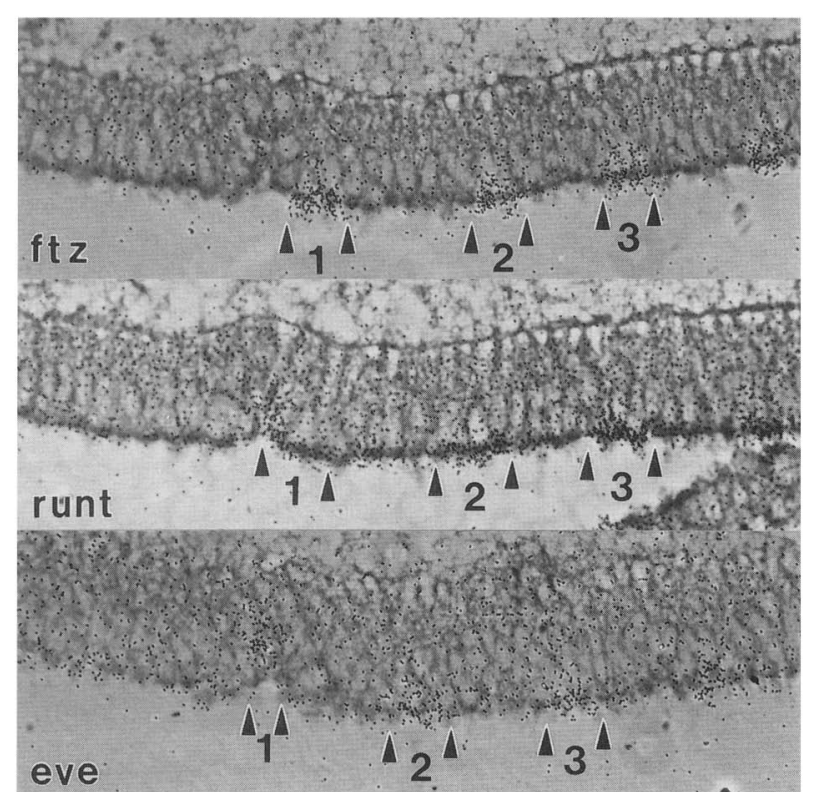

Figure 7. Alignment of stripes from the pair-rule genes runt, $f t z$, and $e v e$. Phase-contrast photomicrographs of in situ hybridization with probes for the pair-rule genes $f t z$, runt, and eve are shown. These were done on consecutive serial sections of the same gastrulating Drosophila embryo. The stripes of expressing cells are indicated by the arrowheads and are numbered. Note, there is expression of runt in the intervals between the original, more heavily labeled stripes.

genes. In contrast to this, $K r$ mRNA was much less restricted and accumulated throughout the cortical cytoplasm within the limits of its domain of expression. Differences in mRNA localization might reflect differences in the degree to which the precise localization of different gene products along the anteroposterior axis is required. Cell membranes grow in from the apical surface and therefore could serve to limit the diffusion of pairrule RNAs and gene products at a stage when gap gene products are not so restricted.

\section{Discussion}

\section{Isolation of the runt gene}

We have cloned the Drosophila segmentation gene runt. Three independent lines of experimental evidence indicate that we have identified DNA segments containing this gene: (1) Six different runt mutations were associated with DNA rearrangements in this region, (2) the sole transcription unit identified in the region was active at the time runt is required and shows a pair-rule pattern, of expression during the blastoderm stage of embryogenesis, and (3) a segment of DNA from this region, when reintroduced into the Drosophila germ-line, provided substantial though not complete runt activity in genetic complementation tests.

\section{The pattern of runt expression}

The pattern of runt transcript accumulation undergoes a series of changes during the early stages of Drosophila embryogenesis. The early evolution of the pattern resembled that of other pair-rule genes. The transcript first appeared with an essentially uniform distribution over a broad domain spanning the soon-to-be-segmented portions of the embryo. This pattern was maintained until the end of nuclear division cycle 13. Then, as the process of cellularization commenced, the pattern changed rapidly. RNA accumulation increased in some regions and disappeared in others, thus giving rise to the characteristic pair-rule pattern of seven stripes. There is substantial evidence indicating that transcriptional regulation accounts for the spatial pattern of expression of the pairrule gene $f t z$ (Edgar et al. 1986; Hiromi and Gehring 1987). Based solely on the rise in the abundance of the runt RNA during the evolution of its pattern, it seems likely that transcriptional regulation also plays an important role here. This is supported by the findings that as is the case for $f t z$, the runt RNA has a short half-life and new protein synthesis is required to repress its accumulation and generate the gaps in the pattern (B. Edgar, pers. comm.l.

The seven-striped pattern of pair-rule gene expression is generally assumed to be the most significant one with respect to the requirements for these different gene products in the process of segmentation. This assumption is based primarily on the correlation between these every-other-segment patterns of gene expression and the pair-rule phenotypes observed in mutant embryos. An additional suggestion that the pair-rule pattern of runt expression is likely to be the one of most developmental importance comes from the observation that the RNA was most abundant at this stage.

A significant aspect of the pattern of runt expression was that even at their narrowest stage, the blastoderm stripes of runt expression were broader than the intervening gaps. This contrasted with other pair-rule genes. It also correlated well with the mutant phenotypes as runt pattern deletions are broader than a segment in width. Analysis of the patterns in animals mosaic for mutations in runt indicated that the requirements are primarily cell autonomous (Gergen and Wieschaus 1985). Therefore, it was expected that the gene would be expressed in domains corresponding to at least the sizes of the pattern deletions. Gene dosage studies indicated extra doses of the runt ${ }^{+}$gene can lead to the deletion of pattern elements that are not affected by loss-of-function mutations (Gergen and Wieschaus 1986). These elements presumably would arise from the gapped regions of the blastoderm runt pattern. This suggests that elimination of runt expression in these regions is an essential aspect of segmentation and furthermore suggests that this process is extremely sensitive to gene dosage.

The pattern of RNA accumulation within runt stripes was not uniform. The most abundant accumulation of RNA was in the middle of the domain. Detailed analysis of mutant phenotypes indicated that within the domains of the runt pattern deletions there is a graded requirement, with the center of each domain being most sensitive to loss of activity (Gergen and Wieschaus 1986). The gene dosage studies also indicated that pattern elements at the margins of the domains were sensitive to both loss 


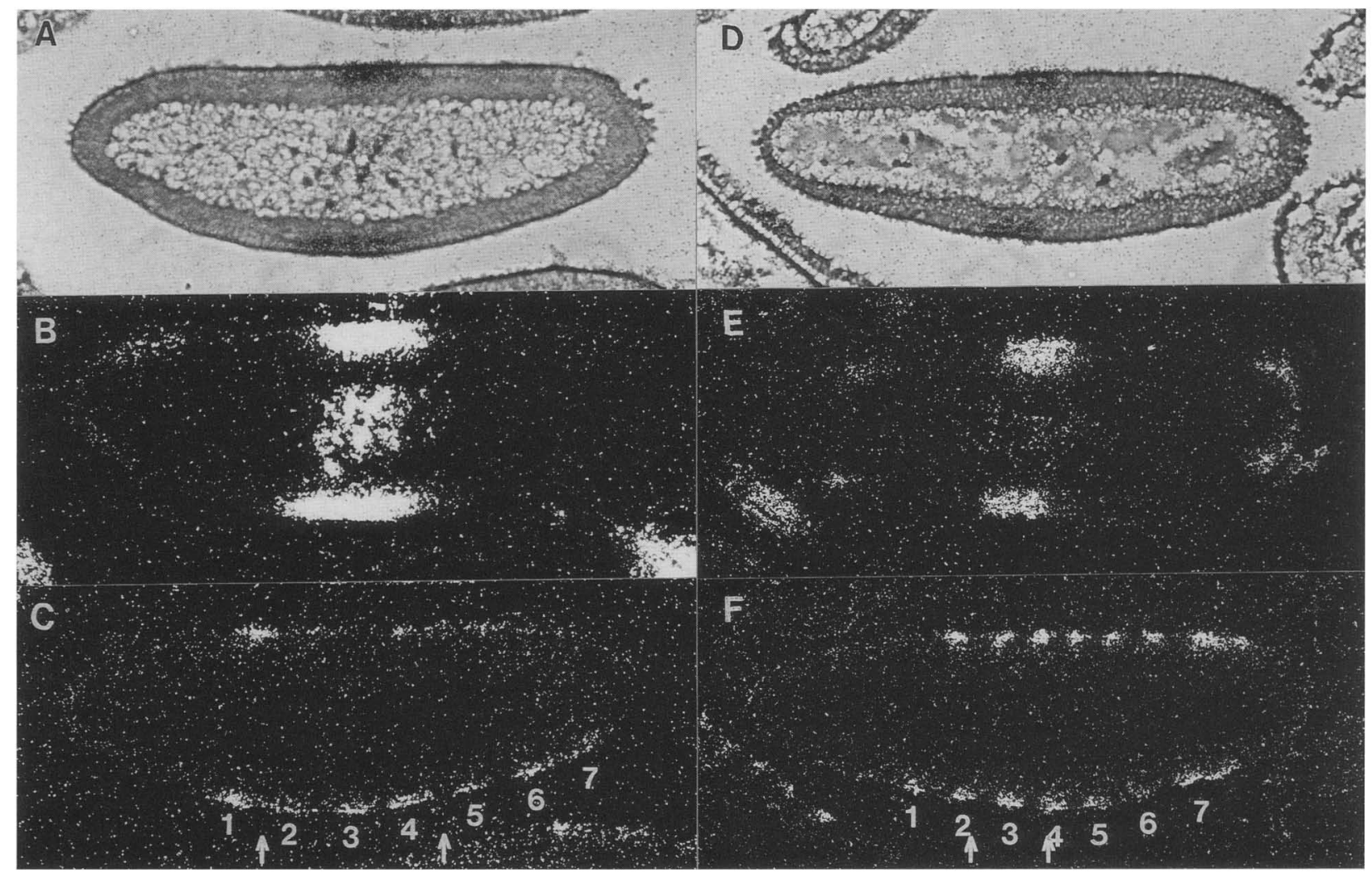

Figure 8. Alignment of runt stripes with domains of $K r$ expression. Dark-field photomicrographs of consecutive serial sections of two Drosophila embryos hybridized with ${ }^{3} \mathrm{H}$ probes for $\operatorname{runt}(B, D)$ and $\operatorname{Kr}(A, C)$. The embryo shown in $A$ and $B$ is early in nuclear division cycle 14. The embryo shown in $C$ and $D$ is midway through the process of cellularization. The arrows indicate the limits of the $K r$ domain relative to the pattern of runt expression. In the older embryo, the $K r$ mRNA is also accumulating at both the anterior and posterior poles. Note that $K r$ expression is not as tightly restricted to the apical regions of the cortex.

and gain of runt activity. This was interpreted as reflecting an obligate requirement for intermediate levels of runt activity in some cells /Gergen and Wieschaus 1986). The apparent correspondence between the graded pattern of RNA accumulation at the blastoderm stage and the requirements as inferred from mutant phenotypes is quite striking. These observations serve to reemphasize the sensitivity of the system to the expression of runt and suggest that at the blastoderm stage the expression of this gene is differentially regulated on a cell-by-cell basis along the anteroposterior axis.

It follows from the observation that runt stripes were broader than a segment in width that they would overlap the segment-wide blastoderm stripes of other pair-rule genes. The phasing of these patterns of expression is for the most part consistent with the phasing of the pattern deletions caused by the mutations in these different genes. For example, the pair-rule eve phenotype has pattern deletions centered over the denticle belts of the even-numbered abdominal segments (Nüsslein-Volhard and Wieschaus 1980). The runt pattern deletions have their anterior margin in the middle of these denticle belts and extend posteriorly to the posterior margin of the next denticle belt (Gergen and Wieschaus 1986). This overlap corresponds to approximately half of the eve do- main. Translating this to the four nuclei-wide stripes of eve blastoderm expression would predict that the two posteriormost rows of eve-expressing nuclei would express runt. Within the limits of the in situ hybridization experiments (about \pm 1 cell), this was the result obtained.

It is of interest to note that the pair-rule runt pattern is, to the limits of our resolution, exactly complementary to the $h$ pattern. This is consistent with the essentially reciprocal effects that mutations in these two genes have on the expression of $f t z$ and eve (Carroll and Scott 1985; Frasch and Levine 1987), and suggests that these genes play analogous yet complementary roles in this regulatory network. One potential model would have runt acting as a repressor of $e v e$, and $h$ as a repressor of $f t z$. However the shift in register between the complementary ftz-eve and $h$-runt patterns suggests that the simplest version of this model is probably incorrect.

It is important to point out that there are some inconsistencies between the phasings of the expression patterns and the mutant phenotypes. The pair-rule eve and $\mathrm{ftz}$ phenotypes would predict that their blastoderm expression patterns would be mostly nonoverlapping but not precisely complementary. The phenotypic differ- 
ences might be due to alterations in the expression of other pair-rule genes caused by eve but not $f t z$ mutations (Harding et al. 1986; Ingham and Gergen, unpubl.) or to differential effects of these mutations on the expression of homeotic genes (Duncan 1986; Ingham and MartinezArias 1986). It will be important to define more precisely the phasing of these and other pair-rule genes to understand the regulatory interactions among these genes and how they act to determine the fates of blastoderm cells. Even so, it is already clear that different combinations of pair-rule genes are expressed in different blastoderm cells on an essentially cell-by-cell basis along the anteroposterior axis.

Based on the genetic analyses of the requirement for runt the less abundant post-blastoderm expression patterns were not expected. The transition of the pattern from a double- to a single-segment mode is reminiscent of phenomena observed with the pair-rule genes prd and eve. Fourteen stripes of prd RNA are apparent by the completion of cellularization (Kilcherr et al. 1986) and weak intervening eve stripes are observed during the process of gastrulation and early germ-band extension (Macdonald et al. 1986). The establishment of every segment periodicity in the pattern of runt expression seems different as the domains of expression were broader and not as well resolved. The expression of runt in regions of the head and proctodeal primordia was not completely unexpected because similar observations have been made for other segmentation genes. Within the head, the runt domain (75-85\% EL) lies posterior to the domains of expression of the pair-rule genes $h(85-95 \% \mathrm{EL}$; Ingham et al. 1985) and prd (87-93\% EL; Kilcherr et al. 1986). In contrast to this there are no obvious differences in the expression patterns of the segmentation genes expressed in the proctodeal primordia. The biological significance of these more anterior and posterior patterns of segmentation gene expression is not known.

\section{The structure of the runt gene}

The runt gene appears to encode a single $2.6-\mathrm{kb}$ mRNA. From the results described here the $5^{\prime}$ end of the mRNA was tentatively placed at position 0.5 on the map in Figure 1. This was primarily based on the observation that fragments to the left of the SalI site at this position did not hybridize to the mRNA, even under conditions where a signal intensity of $1 \%$ of that observed with the hybridizing fragments would be detected. The Southern and Northern blot experiments described here suggest the entire transcription unit was contained within the 14.5 -kb fragment used in the germ-line transformation experiments. Indeed, preliminary sequence analyses of both genomic and cDNA clones and primer extension experiments indicate that the $5^{\prime}$ end of the mRNA is between the Sall sites at 0.5 and 0.78 and that the $3^{\prime}$ end is just distal to the BglII site at position 3.4 (J.P. Gergen and $A$. Bonner, unpubl.). The known mRNAs for other pair-rule genes range from 1.4 to $2.5-\mathrm{kb}$ in size. These are all derived from relatively compact transcriptions units, as appears to be the case for runt. This contrasts dramat- ically with the mRNAs of homeotic genes like Ultrabithorax, which are processed from very long primary transcripts (Hogness et al. 1986). Short transcription units should allow for a more rapid expression of gene products. Mutations in runt have clear and dramatic effects on the expression of other segmentation genes during the blastoderm stage (Carroll and Scott 1986; Frasch and Levine 1987). Therefore, it was expected that the runt transcription unit would be relatively compact.

In contrast with the relative simplicity of the structural gene, the data we present suggest the runt regulatory region is large. The 17-169 mutation is associated with a break that maps 7.5 -kb upstream of the presumptive $5^{\prime}$ end of the mRNA. This mutation has a weak phenotype (Gergen and Wieschaus 1986) and is thought to involve a chromosomal translocation (Schalet and Lefevre 1976). Therefore, this weak phenotype could be due to a position effect. This was a presumption upon which the segment of DNA used for the germ-line transformation experiments was chosen. This $14.5-\mathrm{kb}$ segment spans all of the known breakpoints in runt and extends approximately $0.5-\mathrm{kb}$ upstream of the 17-169 breakpoint. The failure of this segment to provide full activity could also be due to position effects dependent on sites of transposon insertion. However, this seems somewhat unlikely because the two independent lines described here behaved very similarly by our genetic and phenotypic criteria. In addition to these two we have now analyzed another 12 lines carrying this transposon. None of these has the ability to rescue embryos fully from the effects of a null mutation in the runt locus (B.A. Butler and J.P. Gergen, unpubl.). These results suggest strongly that this $14.5-\mathrm{kb}$ segment of DNA does not contain the entire runt gene. Preliminary experiments indicate that doubling the transposon dosage provides more, though still not full, levels of runt activity. This suggests the explanation for the lack of rescue is at least partially due to lower levels of expression from the transposon.

Large regulatory regions have been implicated for other segmentation genes. A $10-\mathrm{kb}$ fragment containing the gap gene $h b$ provides only partial activity in genetic tests (Tautz et al. 1987). Animals bearing mutations in the pair-rule gene $f t z$ are rescued, though not to full viability, by a segment carrying the gene and $6.3-\mathrm{kb}$ of $5^{\prime}-$ flanking DNA (Hiromi et al. 1985). This flanking region contains an enhancer element more than $3-\mathrm{kb}$ upstream from the $5^{\prime}$ end of the mRNA (Hiromi and Gehring 1987). Perhaps the most striking, if not daunting, example is the segment polarity gene engrailed (en). The transcription unit for this gene is only $3.9-\mathrm{kb}$ in size (Drees et al. 1987), whereas mutations define a $70-\mathrm{kb}$ region of DNA required for function (Kuner et al. 1985).

One potentially intriguing insight into the structure of the runt regulatory region comes from a consideration of the dysgenically induced allele 34A. This mutation is due to a chromosomal inversion that breaks approximately $1-\mathrm{kb}$ upstream of the putative $5^{\prime}$ end of the mRNA. This mutation is unusual because it has an almost null phenotype in the region of the second and third abdominal segments yet looks essentially like a 
wild-type in the fourth and fifth abdominal segments. This is unusual not only because of the large discrepancy between adjacent double-segment regions but also because an opposite tendency in pattern deletion sizes is observed for most runt alleles and also for animals carrying half the normal gene dosage (Gergen and Wieschaus 1986). One interpretation is that different runt regulatory elements were used in different parts of the animal and that the 34A inversion has either disrupted or removed some regulatory elements, while leaving others intact. Gap genes are involved in regulating the expression of runt (J.P. Gergen, unpubl.) and different gap genes are required in different parts of the animal. The gap gene products thus provide one set of obvious candidates that could operate through different regulatory elements. A problem with this simple model is that the two regions in question are both affected by mutations in the gap genes $K r$ and knirps. A potential explanation that also complicates any direct interpretation of gap gene phenotypes is derived from the observation that mutations in gap genes alter the domains of expression of other gap genes (Jackle et al. 1986). Because of these interactions, one does not anticipate that the pattern domains affected by mutations in these putative transacting factors would correspond to those affected by disrupting cis-regulatory elements. Further analyses of the cis and trans genetic factors responsible for the regulation of runt should shed light on this issue.

\section{Materials and methods}

\section{Drosophila strains}

The runt mutations $50-2,34 \mathrm{~A}$, and PVl were isolated by Zusman et al. (1985). These were induced on an inverted X chromosome that also carried the dominant $B a r(B)$ mutation. DNA from the parental strain $\operatorname{In}(1) s c^{8}, s c^{8} B$ was used for the wild-type controls in the corresponding genomic Southern blots. The other mutations (LB5, 17-26, and 17-169) were isolated by Schalet and Lefevre (1976). The segmentation phenotypes of these and all other runt mutations used here have been described by Gergen and Wieschaus (1986). The wild-type Oregon $\mathrm{R}$ strain is one that has been isogenized for the third chromosome in the Developmental Genetics Laboratory of the Imperial Cancer Research Fund (Oxford, England). The isogenized $\mathrm{X}$ chromosome stock used for isolating the segments of DNA used in the germ-line transformation experiments carries the yellow $(y)$ mutation and was obtained from Princeton University (Princeton, New Jersey). A strain homozygous for an $\mathrm{X}$ chromosome carrying the $y$ and white ${ }^{67 c 23}$ mutations was used to obtain recipient embryos for the transformation experiments. This strain was also used in subsequent backcrosses for the identification of transformants. Linkage group analysis of integrated transposons was done using stocks carrying the $y$ $w^{67 c 23}$ chromosome and the second and third chromosome balancers $\mathrm{CyO}$ and TM3, Sb Ser, respectively. These chromosomes, $\operatorname{In}(1) s c^{8}$, and the marker mutations have been described by Lindsley and Grell (1968).

\section{Nucleic acids}

Plasmid DNAs were grown using standard procedures (Maniatis et al. 1982) on bacterial strains TG2 (in Oxford, England) or
JM109 or DH5 $\alpha$ (in Houston, Texas). Either the commercial plasmids BlueScribe or BlueScript (Stratagene) which both contain the promoters for T3 and T7 RNA polymerases flanking the polylinker site of insertion, or an analogous plasmid with SP6 and T7 promoters constructed by D. Ish-Horowicz (ICRF, Oxford, England / were used as the vectors. Libraries of DNA in bacteriophage $\lambda$ were originally plated on strain $W L 95$. Positive plaques were rescreened and grown up on WL87. All of the genomic DNA libraries were screened without amplification. The Oregon R library was a generous gift of D. Ish-Horowicz. The in vitro packaging mixes used to make the $50-2$ and isogenized $X$ chromosome libraries were provided by other members of the P. Schedl (Princeton) and D. Ish-Horowicz (Oxford) laboratories, respectively. Of the five different cDNA libraries screened, two were made from poly $(\mathrm{A})^{+} \mathrm{RNA}$ of 0 - to $3-\mathrm{hr}$ embryos and three from 3- to 12 -hr embryos. These were generously provided by the laboratory of T. Kornberg (UCSF, San Francisco, California, see also Poole et al. 1985).

Drosophila DNA was isolated by homogenizing flies in a buffer of $10 \mathrm{~mm}$ Tris (pH 7.5), $60 \mathrm{mM} \mathrm{NaCl}, 10 \mathrm{~mm}$ EDTA, 150 $\mu \mathrm{M}$ of both spermine and spermidine, and $5 \%$ (wt/vol) sucrose. In some cases this homogenate was centrifuged briefly (1000 $\mathrm{rpm}$ in a clinical centrifuge) to remove the carcasses, and the nuclei were pelleted $(8000 \mathrm{rpm}$, Sorvall $)$ and then resuspended in fresh homogenization buffer. Proteinase $\mathrm{K}$ (BoehringerMannheim) and SDS were added to the resulting homogenates to give final concentrations of $100 \mu \mathrm{g} / \mathrm{ml}$ and $1 \%$ (wt $/ \mathrm{vol}$ ), respectively, and the solutions were incubated at $37^{\circ} \mathrm{C}$ for $1 \mathrm{hr}$. This was then extracted twice with an equal volume of phenol and once with chloroform and isoamyl alcohol (24:1). DNA was spooled out with a bent glass rod after adjusting the aqueous phase to $0.25 \mathrm{M} \mathrm{NaCl}$ and adding two volumes of ethanol. DNA was resuspended in TE [TE is $10 \mathrm{mM}$ Tris ( $\mathrm{pH} 7.5), 1$ mM EDTA], reprecipitated with ethanol, and then resuspended to a final concentration of $0.1-1.0 \mathrm{mg} / \mathrm{ml}$ in TE.

RNA was isolated from Oregon $\mathrm{R}$ embryos by first grinding them in a mortar and pestle in liquid nitrogen, and then homogenizing them in TE containing $0.5 \mathrm{M} \mathrm{NaCl}, 0.05 \% \mathrm{SDS}$ (wt/vol) and $100 \mu \mathrm{g} / \mathrm{ml}$ Proteinase $\mathrm{K}$. This homogenate was extracted twice with phenol, and once with chloroform and isoamyl alcohol, and nucleic acid was then precipitated from the aqueous phase with sodium acetate and ethanol. After resuspension in $\mathrm{H}_{2} \mathrm{O}$, the RNA was selectively precipitated away from contaminating DNA by making the solution $3.3 \mathrm{M} \mathrm{LiCl}$ and incubating it for more than $1 \mathrm{hr}$ at $4^{\circ} \mathrm{C}$. RNA was resuspended and subsequently reprecipitated with ethanol before chromatography on oligo(dT)-cellulose (Collaborative Research). RNA from postembryonic stages was a generous gift of R. Schulz (M.D. Anderson Hospital, Houston, Texas|

\section{Gel electrophoresis and blotting}

DNAs were digested with restriction enzymes according to conditions of the commercial supplier, except for digestions of total genomic DNA which also contained $4 \mathrm{~mm}$ spermidine. Electrophoresis and Southern blotting were performed using standard protocols (Maniatis et al. 1982) with the inclusion of the partial DNA hydrolysis step in $0.2 \mathrm{~N} \mathrm{HCl}$ before transfer to nitrocellulose (Schleicher and Schuell). Hybridizations were done at $65^{\circ} \mathrm{C}$ in $2 \times \mathrm{SSC}(1 \times \mathrm{SSC}=0.15 \mathrm{M} \mathrm{NaCl}, 15 \mathrm{~mm}$ sodium citrate) containing $10 \%$ (wt/vol) dextran sulfate (Pharmacia), $500 \mu \mathrm{g} / \mathrm{ml}$ sheared and denatured herring sperm DNA, $10 x$ Denhardt's solution $[100 \times$ Denhardt's $=20 \mathrm{mg} / \mathrm{ml}$ each of Ficoll, polyvinylpyrrolidine, and bovine serum albumin (BSA)], and $0.5 \%$ SDS. In some instances, the dextran sulfate was replaced with $6 \%$ polyethylene glycol (PEG 8000 ) and in other 
cases $50 \mathrm{mM} \mathrm{NaPO}_{4}$, or $50 \mathrm{~mm}$ Tris (pH 7.5) were also included in the hybridization. Blots were washed at a final stringency of $0.2 \times \mathrm{SSC}$ at $65^{\circ} \mathrm{C}$.

Electrophoresis of RNA samples for Northern blots was done on vertical $1 \%$ agarose gels containing $6 \%$ formaldehyde. The electrophoresis buffer was $20 \mathrm{mM}$ HEPES (pH 7.2), $5 \mathrm{~mm}$ sodium acetate, and $1 \mathrm{mM}$ EDTA. RNA was blotted onto nitrocellulose in $20 \times$ SSC and hybridized as above when nick-translated DNA probes were used. With single-stranded RNA probes $60 \%$ formamide (Ultrapure, BRL) was included in the hybridization and it was carried out at $60^{\circ} \mathrm{C}$. RNase $\mathrm{A}$ treatment $(10$ $\mu \mathrm{g} / \mathrm{ml}$ in $\mathrm{TE}+0.5 \mathrm{M} \mathrm{NaCl}$ for $30 \mathrm{~min}$ at $25^{\circ} \mathrm{C}$ ) was used as a final washing step to reduce the background in blots hybridized with single-stranded RNA probes.

Nick-translated probes were synthesized using standard procedures. Single-stranded ${ }^{32} \mathrm{P}$-labeled RNA probes were synthesized from linearized DNA templates using the appropriate RNA polymerase (SP6, T3, or T7). The reaction conditions were as described by Ingham et al. (1985) except that $100 \mu \mathrm{Ci}$ of either $\left[\alpha^{32} \mathrm{P}\right] \mathrm{UTP}$, or $\left[\alpha^{32} \mathrm{P}\right] \mathrm{rCTP}$ (Amersham) was used per labeling reaction. Unlabeled nucleotides were added to give a final concentration of $>10 \mu \mathrm{M}$. Unincorporated label was removed by spun-column chromatography on Sephadex G-50 (DNA probes) or Biogel P-60 (RNA probes) in TE.

\section{Germ-line transformation}

Embryos were injected with a solution containing $5 \mathrm{mM} \mathrm{KCl}$, $0.1 \mathrm{mM} \mathrm{NaPO}{ }_{4}, 0.5-1.0 \mathrm{mg} / \mathrm{ml}$ of the transposon constructs, and $50-100 \mu \mathrm{g} / \mathrm{ml}$ of the wings-clipped helper DNA (Karess and Rubin 1984). The transposon construct used to generate the OP1- and OP2-transformed lines contained a 14.5-kb EcoRI fragment (coordinates -8 to +6.5 in Fig. 1 ) cloned from an isogenic y X chromosome stock into the EcoRI site of CaSpeR. This fragment is oriented so that the runt and $w$ genes were transcribed divergently.

\section{In situ hybridization}

Collection, embedding, sectioning, and hybridization to Drosophila embryos was as described by Ingham et al. (1985). Singlestranded RNA probes were synthesized with $\left[{ }^{3} \mathrm{H}\right] \mathrm{UTP}$ (Amersham). The DNA templates used were: (1) runt-T3 polymerase product of E620-3' cDNA subclone linearized with BamHI, (2) $\mathrm{ftz}$-T7 product of HindIII digested pTftzI (from D. Ish-Horowicz), (3) $K r$-T7 product of Xbal digested pTKrI (from P. Ingham), and (4) eve-SP6 product of XhoI digested p48-X1.4 (Macdonald et al. 1986).

\section{Acknowledgments}

This work was initiated in the laboratory of E. Wieschaus at Princeton University with invaluable assistance from members of P. Schedl's laboratory. J.P.G. would especially like to acknowledge early help from Stuart Tsubota. The cloning and much of the initial characterization of the runt locus was done while J.P.G. was an NSF/NATO postdoctoral fellow in the laboratory of D. Ish-Horowicz at the Imperial Cancer Research Fund Developmental Biology Unit in Oxford, England. The advice, encouragement, and laboratory space provided there are all greatly appreciated. We would like to thank Phil Ingham for his assistance with learning in situ hybridization techniques. This manuscript benefited from the comments of W. Klein and $\mathrm{R}$. Schulz. This work has been supported by the National Institutes of Health (HD 22448) and also by various donors to cancer research at the M.D. Anderson Hospital and Tumor Institute.

\section{References}

Baker, N. E. 1987. Molecular cloning of sequences from wingless, a segment polarity gene in Drosophila: the spatial distribution of a transcript in embryos. EMBO /. 6: 1765-1773.

Baumgartner, S., D. Bopp, M. Burri, and M. Noll. 1987. Structure of two genes at the gooseberry locus related to the paired gene and their spatial expression during Drosophila embryogenesis. Genes Dev. 1: 1247-1267.

Carroll, S. B. and M. P. Scott. 1986. Zygotically active genes that affect the spatial expression of the fushi tarazu segmentation gene during early Drosophila embryogenesis. Cell 45: 113-226.

Carroll, S. B., G. M. Winslow, T. Schupbach, and M. P. Scott. 1986. Maternal control of Drosophila segmentation gene expression. Nature 323: 278-280.

Cote, S., A. Preiss, J. Haller, R. Schuh, A. Kienlin, E. Seifert, and H. Jackle. 1987. The gooseberry-zipper region of Drosophila: five genes encode different spatially restricted transcipts in the embryo. EMBO I. 6: 2793-2801.

DiNardo, S. and P. H. O'Farrell. 1987. Establishment and refinement of segmental pattern in the Drosophila embryo: spatial control of engrailed expression by pair-rule genes. Genes Dev. 1: 1212-1225.

Drees, B., Z. Ali, W. C. Soeller, K. G. Coleman, S. J. Poole, and T. Kornberg. 1987. The transcription unit of the Drosophila engrailed locus: an unusually small portion of a 70,000-bp gene. EMBO I. 6: 2803-2809.

Duncan, I. 1986. Control of Bithorax complex functions by the segmentation gene fushi taraza of $D$. melanogaster. Cell 47: 297-309.

Fjose, A., W. J. McGinnis, and W. E. Gehring. 1985. Isolation of a homeobox containing gene from the engrailed region of Drosophila and the spatial distribution of its transcripts. Nature 313: 284-289.

Frasch, M. and M. Levine. 1987. Complementary patterns of even-skipped and fushi tarazu expression involve their differential regulation by a common set of segmentation genes on Drosophila. Genes Dev. 1: 981-995.

Gaul, U. and H. Jackle. 1987. Pole region-dependent repression of the Drosophila gap gene Krüppel by maternal gene products. Cell 51: 549-555.

Gergen, J. P. and E. Wieschaus. 1985. The localized requirements for a gene affecting segmentation in Drosophila: analysis of larvae mosaic for runt. Dev. Biol. 109: 321-335.

1986. Dosage requirements for runt in the segmentation of Drosophila embryos. Cell 45: 289-299.

Hafen, E., A. Kuroiwa, and W. J. Gehring. 1984. Spatial distribution of transcripts from the segmentation gene fushi tarazu during Drosophila embryonic development. Cell 37: 833841.

Harding, K., C. Rushlow, H. J. Doyle, T. Hoey, and M. Levine. 1986. Cross-regulatory interactions among pair-rule genes in Drosophila. Science 233: 953-959.

Hiromi, Y. and W. J. Gehring. 1987. Regulation and function of the Drosophila segmentation gene fushi tarazu. Cell 50: $963-974$.

Hiromi, Y., A. Kuriowa, and W. J. Gehring. 1985. Control elements of the Drosophila segmentation gene fushi tarazu. Cell 43: 603-613.

Hogness, D. S., H. D. Lipshitz, P. A. Beachy, D. A. Peattie, R. B. Saint, M. Goldschmidt-Clermont, P. J. Harte, E. R. Gavis, and S. L. Helfland. 1986. Regulation and products of the $U b x$ domain of the bithorax complex. Cold Spring Harbor Symp. Quant. Biol. 50: 181-195.

Howard, K. and P. Ingham. 1986. Regulatory interactions be- 
tween the segmentation genes fushi tarazu, hairy, and engrailed in the Drosophila blastoderm. Cell 44: 949-957.

Ingham, P., K. R. Howard, and D. Ish-Horowicz. 1985. Transcription pattern of the Drosophila segmentation gene hairy. Nature 318: 439-445.

Ingham, P. W., D. Ish-Horowicz, and K. R. Howard. 1986. Correlative changes in homeotic and segmentation gene expression in Krüppel mutant embryos of Drosophila. EMBO f. 5: 1659-1665.

Ingham, P.W. and A. Martinez-Arias. 1986. The correct activation of Antennapedia and bithorax complex genes requires the fushi tarazu gene. Nature 324: 592-597.

Jackle, H., D. Tautz, R. Schuh, F. Seifert, and R. Lehmann. 1986. Cross-regulatory interactions among the gap genes of Drosophila. Nature 324: 668-670.

Karess, R. E., and G. M. Rubin. 1984. Analysis of P-transposable element functions in Drosophila. Cell 38: 135-146.

Kilcherr, F., S. Baumgartner, D. Bopp, E. Frei, and M. Noll. 1986. Isolation of the paired gene of Drosophila and its spatial expression during early embryogenesis. Nature 321: 493-499.

Knipple, D. C., E. Seifert, U. B. Rosenberg, A. Priess, and H. Jackle. 1985. Spatial and temporal patterns of Krüppel gene expression in early Drosophila embryos. Nature 317: 4044.

Kornberg, T., I. Siden, P. O'Farrell, and M. Simon. 1985. The engrailed locus of Drosophila: in situ localization of transcripts reveals compartment specific expression. Cell 40: 45-53.

Kuner, J. M., M. Nakanishi, Z. Ali, B. Dress, E. Gustavson, J. Theis, L. Kauvar, T. Kornberg, and P. H. O'Farrell. 1985. Molecular cloning of engrailed: A gene involved in the development of pattern in Drosophila melanogaster. Cell 42: 309316.

Lindsley, D. L. and E. H. Grell. 1968. Genetic variations in Drosophila melanogaster. Carnegie Institute of Washington Publication 627.

Macdonald, P. M., P. Ingham, and G. Struhl. 1986. Isolation, structure, and expression of even-skipped: A second pairrule gene of Drosophila containing a homeobox. Cell 47: $721-734$.

Maniatis, T., E. F. Fritsch, and S. Sambrook. 1982. Molecular cloning. A laboratory manual. Cold Spring Harbor Laboratory, Cold Spring Harbor, New York.

Mohler, J. and E. F. Wieschaus. 1985. Bicaudal mutations of Drosophila melanogaster: Alternation of blastoderm cell fate. Cold Spring Harbor Symp. Quant. Biol. 50: 105-111.

Nüsslein-Volhard, C., H. G. Frohnhofer, and R. Lehmann. 1987. Determination of anteroposterior polarity in Drosophila. Science 238: 1675-1681.

Nüsslein-Volhard, C., and E. Wieschaus. 1980. Mutants affecting segment number and polarity in Drosophila. Nature 287: 795-801.

O'Hare, K., and G. M. Rubin. 1983 Structures of P-transposable elements and their sites of insertion and excision in the Drosophila melanogaster genome. Cell 34: 25-35.

Poole, S. J., L. M. Kauvar, B. Drees, and T. Kornberg. 1985. The engrailed locus of Drosophila: structural analysis of an embryonic transcript. Cell 40: 37-43.

Rijsewijk, F., M. Schuermann E. Wagenaar, P. Parren, D. Weigel, and R. Nusse. 1987. The Drosophila homolog of the mouse mammary oncogene int- 1 is identical to the segment polarity gene wingless. Cell 50: 649-657.

Rubin, G. M., and A. C. Spradling. 1982 Genetic transformation of Drosophila with transposable element vectors. Science 218: $348-353$.
Schalet, A., and G, Lefevre, Ir. 1976. The proximal region of the $\mathrm{X}$ chromosome. In The genetics and biology of Drosophila Vol. 1B (ed. M. Ashburner and E. Novitski), pp. 847-902. Academic Press, London.

Schupbach, T., and E. Wieschaus. 1986. Maternal-effect mutations altering the antero-posterior patterns of the Drosophila embryo. Wilhelm Roux's Archv. Dev. Biol. 195: 302317.

Tautz, D., R. Lehman, H. Schnurch, R. Schuh, E. Seifert, A. Kienlin, K. Jones, and H. Jackle. 1987. Finger protein of novel structure encoded by hunchback, a second member of the gap class of Drosophila segmentation genes. Nature 327: 383-389.

Zusman, S., D. Coulter, and J. P. Gergen. 1985. Lethal mutations induced in the proximal X-chromosome of Drosophila melanogaster using P-M hybrid dysgenesis. Dros. Inf. Serv. 61: $217-218$. 


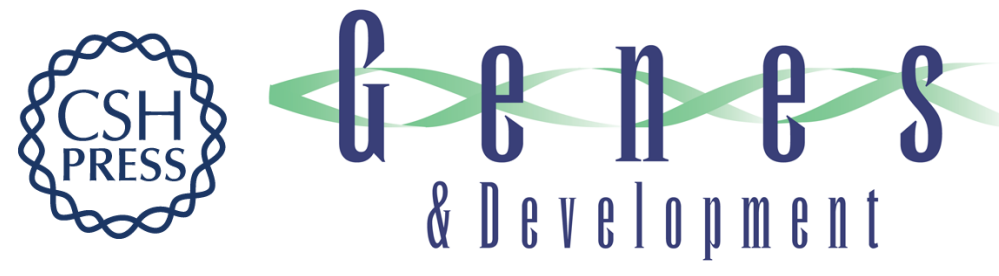

\section{Isolation of the Drosophila segmentation gene runt and analysis of its expression during embryogenesis.}

J P Gergen and B A Butler

Genes Dev. 1988, 2:

Access the most recent version at doi:10.1101/gad.2.9.1179

References This article cites 39 articles, 7 of which can be accessed free at:

http://genesdev.cshlp.org/content/2/9/1179.full.html\#ref-list-1

License

Email Alerting

Service

Receive free email alerts when new articles cite this article - sign up in the box at the top right corner of the article or click here.

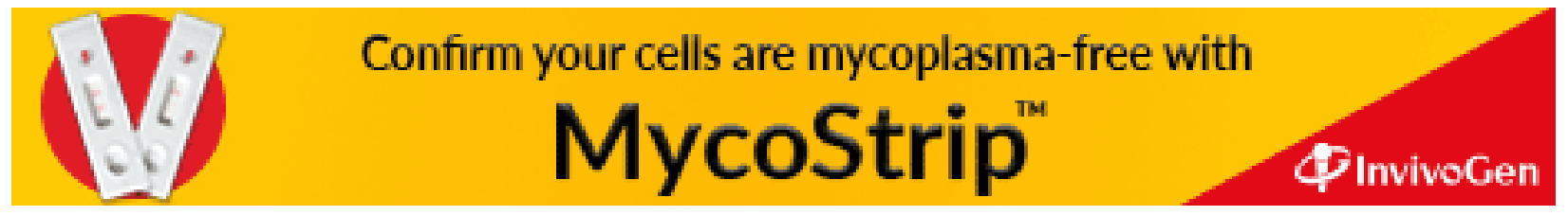

